\title{
Kinetochore assembly: If you build it, they will come
}

\author{
Karen E. Gascoigne and lain M. Cheeseman \\ Karen E. Gascoigne: karengas@wi.mit.edu; lain M. Cheeseman: icheese@wi.mit.edu
}

\section{Abstract}

Accurate chromosome segregation requires the interaction of chromosomes with the microtubules from the mitotic spindle. This interaction is mediated by the macro-molecular kinetochore complex, which assembles only at the centromeric region of each chromosome. However, how this site is specified and how assembly of the kinetochore structure is regulated in coordination with cell cycle progression remains unclear. Recent studies have begun to shed light on the mechanisms underlying assembly of this complex structure.

\section{Keywords}

Mitosis; chromosome segregation; kinetochore

\section{Introduction}

During mitosis, cells must accurately partition their genome such that genetic information is transferred unperturbed to the progeny. In eukaryotes, accurate chromosome segregation requires each chromosome to interact appropriately with microtubules from the mitotic spindle that provides the structural framework upon which chromosome segregation occurs. This interaction is mediated by the macromolecular kinetochore complex, a structure of more than 90 proteins that assembles at the centromeric region of each chromosome during mitosis [1]. The kinetochore must facilitate the interaction between centromeric chromatin and dynamic microtubules to facilitate the biorientation of chromosomes on the metaphase plate and the segregation of sister chromatids at anaphase.

Conventional electron microscopy studies indicated that the kinetochore has a layered structure, with an electron dense inner plate that contacts centromeric chromatin, an outer plate that contacts microtubules, and a "fibrous corona" that extends away from the outer plate [2]. The majority of this structure is not present during interphase, assembling only upon entry into mitosis when the interaction with microtubules is required, and disassembling upon mitotic exit. In recent years, advances in proteomic approaches have greatly expanded the catalogue of kinetochore components [1]. However, while the functions of many of these individual components have been defined, surprisingly little is known about how they are recruited to the centromere, and how they interact to assemble the complex kinetochore structure. Moreover, how this process is regulated to ensure timely assembly of the kinetochore upon mitotic entry, and disassembly of the structure upon

Whitehead Institute for Biomedical Research, and Department of Biology, Massachusetts Institute of Technology, Nine Cambridge Center, Cambridge, MA 02142, Phone: (617) 324-2503, Fax: (617) 258-5578.

Publisher's Disclaimer: This is a PDF file of an unedited manuscript that has been accepted for publication. As a service to our customers we are providing this early version of the manuscript. The manuscript will undergo copyediting, typesetting, and review of the resulting proof before it is published in its final citable form. Please note that during the production process errors may be discovered which could affect the content, and all legal disclaimers that apply to the journal pertain. 
completion of mitosis, is poorly understood. Here, we highlight recent advances in our understanding of kinetochore assembly and disassembly in human cells, as well as potential mechanisms that regulate this process.

\section{Specifying the site of kinetochore assembly}

For accurate chromosome segregation to occur, it is crucial the kinetochore assembles at only one site on each chromosome. The properties of the centromere that mark it as the site for kinetochore formation include a combination of epigenetic marks such as the presence of CENP-A (Centromere Associated Protein-A) containing nucleosomes, chromatin structure, and DNA sequence properties (reviewed in [3]). Deposition of the histone H3 variant CENP-A occurs predominantly at centromeres and is required for kinetochore assembly [46]. Recently, high resolution structural data for a CENP-A/H4 heterotetramer has been reported, showing significant structural differences between this, and canonical $\mathrm{H} 3$ containing nucleosomes. These differences are essential for centromeric incorporation of CENP-A nucleosomes [7], and may also reflect a contribution of CENP-A to a specialized chromatin structure at the base of kinetochores. Surprisingly, in mammalian cells, while CENP-A nucleosomes are required for kinetochore assembly, the presence of the alpha satellite DNA sequences that are typically associated with centromeres is not. In humans, this is demonstrated most strikingly by the rare occurrence of neo-centromeres at ectopic chromosomal loci devoid of alpha satellite sequences [8]. At these sites CENP-A is deposited, along with a number of other kinetochore proteins, in the absence of alpha satellite sequences [9]

Unlike canonical histone molecules that are loaded into chromatin during DNA replication, CENP-A is equally segregated between sister chromatids during $\mathrm{S}$ phase, but new CENP-A is not incorporated into centromeric chromatin until telophase and G1 [10,11]. The significance of this unusual timing is unclear, but could represent a mechanism to guard against mis-incorporation and the consequent assembly of kinetochore structures at noncentromeric sites by temporally separating the incorporation of CENP-A from the replication-coupled incorporation of other histones. Ubiquitin-dependent proteolysis of CENP-A incorporated at non-centromeric sites may also act to guard against this misincorporation [12]. Other kinetochore components may also act to regulate this process. In Drosophila, tightly controlled levels of the CENP-A/CENP-C bridging factor Cal1 may prevent incorporation at non-centromeric sites [13]. However, an active mechanism for recruitment of CENP-A to centromeres is still essential. The Mis 18 complex of proteins is required for the incorporation and maintenance of CENP-A [14-16]. The HJURP/Smc3 chaperone protein has also been implicated in the centromeric loading of CENP-A [**17,**18]. HJURP directly interacts with prenucleosomal CENP-A/H4 complexes via the centromere-targeting domain of CENP-A, and is required for the deposition of CENP-A in G1. HJURP is recruited to centromeres slightly later than Mis18, which is present from late anaphase to early G1. The Mis18 complex may act as a primer for the loading of CENP-A, which is in turn facilitated by a chaperone complex including HJURP (Figure 1). Thus, the mechanisms that initiate the processes of kinetochore assembly by specifying its a chromosomal position are beginning to be understood.

\section{Architecture of the Human Kinetochore}

Although CENP-A is sufficient to drive kinetochore formation in Drosophila [*19], in human cells the presence of CENP-A is not sufficient for complete kinetochore assembly during mitosis [20]. Additional proteins are also found constitutively at the human centromere throughout the cell cycle, and are required for correct assembly of the mitotic structure. In particular, functional and proteomic approaches have identified a group of 15 
proteins known as the Constitutive Centromere Associated Network (CCAN) [21-*23-25] (Figure 1). Functional analyses have suggested that these proteins primarily play a structural role in forming a stable base for dynamic kinetochore assembly, as well as providing an appropriate environment for the incorporation of new CENP-A [21,23,25-28]. However, a recent study also suggested that the CCAN may also function to directly control microtubule dynamics [24]. Dissecting the role of these proteins in structural support and assembly versus a direct role in microtubule interactions will be an important for future work.

The CCAN proteins are found at the kinetochore-chromatin interface, and several of these proteins have been shown to have DNA binding activity $[23,29,30]$ or directly interact with CENP-A [*31,32]. As these proteins remain associated with centromeric chromatin throughout the cell cycle, in conjunction with CENP-A they may form a stable, permissive environment for the assembly of the mitotic kinetochore structure. The outer kinetochore plate and fibrous corona assemble upon entry into mitosis, and contain proteins required for interactions with microtubules. This includes proteins with direct microtubule binding activity, such as the KMN (KNL1, Mis12, Ndc80) network (reviewed in [1], the Ska1 complex [33], and CENP-E [34], as well as more transient factors that modulate this interaction or monitor attachment status (Figure 1).

Recent work using super-resolution light microscopy techniques [**35] has mapped the internal architecture of the kinetochore in the presence and absence of tension across kinetochore pairs, and identified surprising changes in the organization of the structure. For example, in the absence of tension, the distance between inner kinetochore proteins, such as CENP-C, and the microtubule interacting Ndc80 complex was reduced. However, the localization of inner kinetochore proteins with respect to each other remained unchanged. Reduction in the tension across kinetochores also caused a striking rearrangement of components of the KMN network, suggesting some kinetochore protein complexes are more compliant than others in response to forces exerted by microtubule interactions.

FRET (fluorescence resonance energy transfer) based approaches have also been used to position proteins with respect to each other within the kinetochore ultrastructure [36]. FRET measurements between selected pairs of CCAN proteins indicated that during interphase, specific components of the CCAN complex are located close together at the centromere. For example, high FRET measurements were observed between CENP-U and CENP-I, and CENP-U and CENP-B. In the future, the use of this approach to systematically map the localization of known kinetochore components, in parallel with proteomic and functional analysis, will allow the formation of a detailed picture of kinetochore structure and assembly pathways.

\section{Turnover of Kinetochore Proteins}

While at first glance the bulk of the kinetochore structure appears stable at the centromere throughout mitosis, recent work suggests that kinetochore proteins are actually highly dynamic. Outer kinetochore components recruited in mitosis can be divided into two groups; 1) those that form the stable core of the kinetochore responsible for achieving and maintaining microtubule attachment, and 2) those whose association with the kinetochore structure is more transient and is influenced by the attachment state of the kinetochore. Outer kinetochore proteins involved in sensing attachments and spindle checkpoint signaling are very dynamic. FRAP (Fluorescence Recovery After Photo-bleaching) experiments indicated that the checkpoint protein Mad2 has a half-life at the kinetochore of just seconds [37,38] (figure 1). In contrast, these studies indicate that stable components, such as CENP$\mathrm{C}$ or Ndc80 (Figure 1), have much longer residencies, remaining immobile at the kinetochore throughout mitosis $[37,39]$. Recent work has indicated that even some 
constitutive kinetochore proteins are dynamic. For example, during interphase, pools of Mis12, CENP-C and CENP-B have relatively short half-lives at kinetochores [40].

\section{Driving kinetochore assembly}

The overall kinetochore composition is highly dynamic through the cell cycle. Inner kinetochore proteins such as the CCAN are present at the centromere throughout the cell cycle, while some outer kinetochore proteins such as Mis12 complex and KNL1 are recruited in G2 [25] (Figure 1). This assembly prior to mitosis presumably acts to prime the centromere for assembly of the remaining components, which occurs at prophase and prometaphase to generate a structure capable of binding to microtubules.

Work on kinetochore assembly has primarily used reciprocal dependency relationships to define the requirements for localization to kinetochores and to place proteins within the kinetochore assembly hierarchy $[25,28,41,42]$. For example, depletion of CENP-A from $C$. elegans prevents the localization of CENP-C to chromosomes, while CENP-C depletion has no effect on CENP-A localization suggesting that CENP-A functions upstream of CENP-C $[6,43]$. Using such pairwise assays, it has been possible to construct extensive maps of the dependency relationships for the yeast, $C$. elegans, Drosophila, and human kinetochores. While there are some minor differences in these relationships in different organisms (for example, the localization of CENP-A and CENP-C localization is interdependent in Drosophila [44]), the fundamental principles of this organization are largely conserved. Importantly, directed biochemical experiments defining the physical interactions between components of the kinetochore has largely supported these dependency relationships $[21,26,27,31,45]$.

Based on the work that has been conducted to date, we suggest that there are four primary types of proteins that contribute to kinetochore assembly; linkers, scaffolds, chaperones, and structural stabilizers. As might be expected based on the more than 90 proteins that are stably associated with the mitotic kinetochore, a subset of proteins must function to build the molecular connectivity between centromeric DNA and microtubule polymers. These proteins, which we term "linkers", would bind to both a DNA proximal protein and a more peripheral protein to hold these together. For example, the Mis 12 complex associates with inner kinetochore proteins, and also binds to the outer kinetochore proteins KNL1 and the Ndc80 complex [46] (Figure 1). However, it is important to note that such linker proteins do not need to simply bridge molecular interactions. In the case of the Mis 12 complex, our recent work has suggested that it functions to position the KNL1 and Ndc80 complexes in a way that promotes their individual microtubule binding activities [47].

While proteins such as the Mis 12 complex would function to link together components of the kinetochore, "scaffold" proteins would provide a broader platform for the assembly of distinct components of the kinetochore. In this context, KNL1 (also named Spc105 or Blinkin), appears to provide such a scaffold within the kinetochore. To date, KNL1 has been demonstrated to bind directly to the Mis 12 complex, the Ndc80 complex, the spindle assembly checkpoint proteins Bub1 and BubR1, the outer kinetochore protein Zwint, the protein phosphatase PP1, and microtubules [46,48-50]. In this way, KNL1 can coordinate multiple different activities at the outer kinetochore (Figure 1).

A subset of proteins appear to function in kinetochore assembly despite not stably localizing to the kinetochore themselves. These kinetochore "chaperones" function to bring proteins to the kinetochore, or stabilize their proper incorporation. For example, hJURP appears to function as a CENP-A-specific nucleosome assembly factor, facilitating its recruitment kinetochores $[17,18]$. Recent work has also implicated Skp1 and Hsp90 in kinetochore assembly by acting to recruit and stabilize the Mis12 complex [*51] (Figure 1). 
Although the process of building a kinetochore by recruiting proteins to the centromere is critical for chromosome segregation during mitosis, it is also important that the final assembled structure be capable of withstanding the large forces that are exerted upon it. Indeed, the formation of bi-oriented attachments is capable of stretching an individual kinetochore structure by more than $60 \mathrm{~nm}$. Recent work has suggested that a subset of kinetochore proteins, including a complex of CENP-S and CENP-X, may function to maintain structural rigidity, but not directly contribute to the localization of other components [52]. Thus, CENP-S/X may function as structural "stabilizers" such that their depletion results in a kinetochore structure that is much less rigid and compact despite an apparently normal complement of kinetochore proteins (Figure 1).

\section{The control of kinetochore assembly and disassembly by post-translational modifications}

A striking feature of the vertebrate kinetochore is the massive reorganization that takes place during mitosis. During a time span of less than one hour, the kinetochore must recruit more than 40 mitosis-specific components to facilitate attachment to microtubules, and then subsequently disassemble these proteins to return to an interphase state. There are several possibilities for how the association of these proteins with the kinetochore could be controlled. First, the presence of the nuclear envelope may restrict a subset of proteins from the nucleus such that they are unable to associate with the kinetochore until Nuclear Envelope Break Down (NEBD). For example, nuclear pore complex components such as the Nup107-160 complex relocalize from the nuclear envelope to the kinetochore upon NEBD, and then leave the kinetochore during early anaphase as the nuclear envelope reforms [53,54]. Disassembly of the nuclear envelope likely liberates this complex, making it available for kinetochore binding. Similarly, the reformation of the nuclear envelope on mitotic exit could then sequester the complex away from the centromere (Figure 1). The nuclear envelope may similarly act to block the assembly of other mitosis-specific proteins. However, recent work has demonstrated that at least a subset of proteins are present within the nucleus at times when they do not localize to kinetochores [25], suggesting that this is not true in every case.

While the presence of the nuclear envelope may function to control the assembly of some kinetochore proteins, it is also possible that the expression of mitotic kinetochore proteins may be coupled with the cell cycle such that these proteins are not present during interphase. However, in the cases tested so far, constitutive basal expression of GFP kinetochore protein fusions has revealed identical localization to that of the endogenous counterparts as detected by immunofluorescence $[21,25,42,46]$, suggesting that this does not play a major role in controlling kinetochore assembly.

A third possibility is that the stability of individual proteins may be altered during mitosis, such as by targeting specific proteins for degradation. Recent work has demonstrated that the ubiquitin-like protein SUMO modifies the kinetochore protein CENP-I [*55]. When CENP-I is extensively SUMOylated, it is targeted for degradation. Thus, the correct incorporation of CENP-I into kinetochores requires the action of the SUMO protease SENP6 to remove this SUMOlation (Figure 1). In addition, several kinetochore components including Aurora B, Polo Like Kinase-1 (PLK-1), CENP-E, and CENP-F are known to be degraded at the end of mitosis via the Anaphase Promoting Complex (APC) ubiquitin ligase and the proteosome [56,57].

Finally, it is possible that kinetochore proteins are also carefully regulated by posttranslational modifications, such as phosphorylation, in coordination with the cell cycle to control their assembly and disassembly occurs at specific times. Indeed, there have been 
several recent reports that have implicated post-translational modifications in the control of kinetochore assembly. The most obvious candidate for a kinase that would affect the mitotic assembly state of the kinetochore is Cyclin Dependent Kinase (CDK). However, due to the numerous roles of $\mathrm{CDK}$ in controlling cell cycle progression, thus far it has not been possible to define a specific role for CDK phosphorylation in kinetochore assembly. In contrast, although Aurora B kinase has been primarily implicated in controlling kinetochoremicrotubule attachments by modulating the microtubule binding activity of key kinetochore proteins $[45,58,59]$, studies in budding yeast and Xenopus extracts have suggested that Aurora B activity is also required for proper kinetochore assembly [60]. However, the effects observed in Xenopus extracts do not appear to be as dramatic following Aurora B inhibition in human cells [47]. Thus, the relative contribution of Aurora B to kinetochore assembly remains to be determined. Finally, recent work has demonstrated the Bub1 kinase phosphorylates a conserved site on Histone H2A [**61]. Phosphorylation of this site appears to create a binding site for the regulatory protein Sgo1 to allow it to target to kinetochores. In total, it is likely that a coordinated combination of mechanisms acts to regulate the highly ordered process of kinetochore assembly and disassembly.

\section{Conclusions and Future directions}

Recent work to define the composition of the kinetochore and the nearly complete parts list of its components has yielded important information regarding the organization and function of this vital mitotic structure. As highlighted in this review, while some regulatory events that control kinetochore assembly have been identified, it remains a key goal to define the mechanisms by which this dynamic multi-protein assembly is built and disassembled during mitosis.

\section{Acknowledgments}

We thank Tom DiCesare for help turning our rough sketch into a pretty figure.

\section{References}

1. Cheeseman IM, Desai A. Molecular architecture of the kinetochore-microtubule interface. Nat Rev Mol Cell Biol 2008;9:33-46. [PubMed: 18097444]

2. McEwen BF, Dong Y. Contrasting models for kinetochore microtubule attachment in mammalian cells. Cell Mol Life Sci 2010;67:2163-2172. [PubMed: 20336345]

3. Dalal Y, Bui M. Down the rabbit hole of centromere assembly and dynamics. Curr Opin Cell Biol. 2010

4. Howman EV, Fowler KJ, Newson AJ, Redward S, MacDonald AC, Kalitsis P, Choo KH. Early disruption of centromeric chromatin organization in centromere protein A (Cenpa) null mice. Proc Natl Acad Sci U S A 2000;97:1148-1153. [PubMed: 10655499]

5. Black BE, Jansen LE, Maddox PS, Foltz DR, Desai AB, Shah JV, Cleveland DW. Centromere identity maintained by nucleosomes assembled with histone $\mathrm{H} 3$ containing the CENP-A targeting domain. Mol Cell 2007;25:309-322. [PubMed: 17244537]

6. Oegema K, Desai A, Rybina S, Kirkham M, Hyman AA. Functional analysis of kinetochore assembly in Caenorhabditis elegans. J Cell Biol 2001;153:1209-1226. [PubMed: 11402065]

7. Sekulic N, Bassett EA, Rogers DJ, Black BE. The Structure of the (CENP-A/H4)2 Reveals Physical Features that Mark Centromeres. Nature. 2010 In press.

8. Amor DJ, Choo KHA. Neocentromeres: role in human disease, evolution, and centromere study. Am J Hum Genet 2002;71:695-714. [PubMed: 12196915]

9. Bassett EA, Wood S, Salimian KJ, Ajith S, Foltz DR, Black BE. Epigenetic centromere specification directs autot $\mathrm{B}$ accumulation but is insufficient to efficiently correct mitotic errors. $\mathrm{J}$ Cell Biol. 2010 In press. 
10. Jansen LET, Black BE, Foltz DR, Cleveland DW. Propagation of centromeric chromatin requires exit from mitosis. The Journal of Cell Biology 2007;176:795-805. [PubMed: 17339380]

11. Schuh M, Lehner CF, Heidmann S. Incorporation of Drosophila CID/CENP-A and CENP-C into centromeres during early embryonic anaphase. Curr Biol 2007;17:237-243. [PubMed: 17222555]

12. Collins KA, Furuyama S, Biggins S. Proteolysis contributes to the exclusive centromere localization of the yeast Cse4/CENP-A histone H3 variant. Curr Biol 2004;14:1968-1972. [PubMed: 15530401]

13. Schittenhelm RB, Althoff F, Heidmann S, Lehner CF. Detrimental incorporation of excess CENPA/Cid and CENP-C into Drosophila centromeres is prevented by limiting amounts of their bridging factor Cal1. J Cell Sci. 2010 In Press.

14. Maddox PS, Hyndman F, Monen J, Oegema K, Desai A. Functional genomics identifies a Myb domain-containing protein family required for assembly of CENP-A chromatin. J Cell Biol 2007;176:757-763. [PubMed: 17339379]

15. Fujita Y, Hayashi T, Kiyomitsu T, Toyoda Y, Kokubu A, Obuse C, Yanagida M. Priming of centromere for CENP-A recruitment by human hMis18alpha, hMis18beta, and M18BP1. Dev Cell 2007;12:17-30. [PubMed: 17199038]

16. Hayashi T, Fujita Y, Iwasaki O, Adachi Y, Takahashi K, Yanagida M. Mis16 and Mis18 are required for CENP-A loading and histone deacetylation at centromeres. Cell 2004;118:715-729. [PubMed: 15369671]

17**. Foltz DR, Jansen LE, Bailey AO, Yates JR 3rd, Bassett EA, Wood S, Black BE, Cleveland DW. Centromere-specific assembly of CENP-a nucleosomes is mediated by HJURP. Cell 2009;137:472-484. Together with Dunleavy et al 2009, this paper reports the discovery of a CENP-A "chaperone" required for incorporation of CENP-A nucleosomes into centromeric chromatin. [PubMed: 19410544]

18**. Dunleavy EM, Roche D, Tagami H, Lacoste N, Ray-Gallet D, Nakamura Y, Daigo Y, Nakatani Y, Almouzni-Pettinotti G. HJURP Is a Cell-Cycle-Dependent Maintenance and Deposition Factor of CENP-A at Centromeres. Cell 2009;137:485-497. Together with Foltz et al 2009, this paper reports the discovery of a CENP-A "chaperone" required for incorporation of CENP-A nucleosomes into centromeric chromatin. [PubMed: 19410545]

19*. Heun P, Erhardt S, Blower MD, Weiss S, Skora AD, Karpen GH. Mislocalization of the Drosophila centromere-specific histone CID promotes formation of functional ectopic kinetochores. Dev Cell 2006;10:303-315. This paper shows that over-expression of the centromeric histone CID in Drosophila causes its mis-incoporation into chromosome arms and the formation of ectopic kinetochore sites. [PubMed: 16516834]

20. Van Hooser AA, Ouspenski II, Gregson HC, Starr DA, Yen TJ, Goldberg ML, Yokomori K, Earnshaw WC, Sullivan KF, Brinkley BR. Specification of kinetochore-forming chromatin by the histone H3 variant CENP-A. J Cell Sci 2001;114:3529-3542. [PubMed: 11682612]

21. Foltz DR, Jansen LET, Black BE, Bailey AO, Yates JR, Cleveland DW. The human CENP-A centromeric nucleosome-associated complex. Nat Cell Biol 2006;8:458-469. [PubMed: 16622419]

22. Okada M, Okawa K, Isobe T, Fukagawa T. CENP-H-containing Complex Facilitates Centromere Deposition of CENP-a in Cooperation with FACT and CHD1. Mol Biol Cell. 2009

23*. Hori T, Amano M, Suzuki A, Backer CB, Welburn JP, Dong Y, Mcewen BF, Shang W-H, Suzuki E, Okawa K, et al. CCAN Makes Multiple Contacts with Centromeric DNA to Provide Distinct Pathways to the Outer Kinetochore. Cell 2008;135:1039-1052. This paper reveals the DNA binding properties of CENP-T, and its role in kinetochore assemby. [PubMed: 19070575]

24. Amaro AC, Samora CP, Holtackers R, Wang E, Kingston IJ, Alonso M, Lampson M, McAinsh $\mathrm{AD}$, Meraldi P. Molecular control of kinetochore-microtubule dynamics and chromosome oscillations. Nat Cell Biol 2010;12:319-329. [PubMed: 20228811]

25. Cheeseman IM, Hori T, Fukagawa T, Desai A. KNL1 and the CENP-H/I/K complex coordinately direct kinetochore assembly in vertebrates. Mol Biol Cell 2008;19:587-594. [PubMed: 18045986]

26. Hori T, Okada M, Maenaka K, Fukagawa T. CENP-O class proteins form a stable complex and are required for proper kinetochore function. Mol Biol Cell 2008;19:843-854. [PubMed: 18094054] 
27. Okada M, Cheeseman IM, Hori T, Okawa K, Mcleod IX, Yates JR, Desai A, Fukagawa T. The CENP-H-I complex is required for the efficient incorporation of newly synthesized CENP-A into centromeres. Nature Cell Biology 2006;8:446-457.

28. Liu S-T, Rattner JB, Jablonski SA, Yen TJ. Mapping the assembly pathways that specify formation of the trilaminar kinetochore plates in human cells. The Journal of Cell Biology 2006;175:41-53. [PubMed: 17030981]

29. Masumoto H, Masukata H, Muro Y, Nozaki N, Okazaki T. A human centromere antigen (CENPB) interacts with a short specific sequence in alphoid DNA, a human centromeric satellite. J Cell Biol 1989;109:1963-1973. [PubMed: 2808515]

30. Sugimoto K, Yata H, Muro Y, Himeno M. Human centromere protein C (CENP-C) is a DNAbinding protein which possesses a novel DNA-binding motif. J Biochem 1994;116:877-881. [PubMed: 7883764]

31*. Carroll CW, Silva MCC, Godek KM, Jansen LET, Straight AF. Centromere assembly requires the direct recognition of CENP-A nucleosomes by CENP-N. Nat Cell Biol 2009:1-15. This paper is the first to identify a kinetochore protein $(\mathrm{CENP}-\mathrm{N})$ that directly interacts with CENP-A in human cells.

32. Carroll CW, Milks KJ, Straight AF. Dual recognition of CENP-A nucleosomes is required for centromere assembly. J Cell Biol 2010;189:1143-1155. [PubMed: 20566683]

33. Welburn JPI, Grishchuk EL, Backer CB, Wilson-Kubalek EM, Yates JR, Cheeseman IM. The human kinetochore Ska1 complex facilitates microtubule depolymerization-coupled motility. Dev Cell 2009;16:374-385. [PubMed: 19289083]

34. Wood KW, Sakowicz R, Goldstein LS, Cleveland DW. CENP-E is a plus end-directed kinetochore motor required for metaphase chromosome alignment. Cell 1997;91:357-366. [PubMed: 9363944]

$35^{* *}$. Wan X, O•Quinn RP, Pierce HL, Joglekar AP, Gall WE, Deluca JG, Carroll CW, Liu S-T, Yen TJ, Mcewen BF, et al. Protein Architecture of the Human Kinetochore Microtubule Attachment Site. Cell 2009;137:672-684. This study uses super-resolution light microscopy techniques to map the position kinetochore proteins with respect to each other, and identifies important architectural changes in the structure in the presence and absence of tension. [PubMed: 19450515]

36. Hellwig D, Hoischen C, Ulbricht T, Diekmann S. Acceptor-photobleaching FRET analysis of core kinetochore and NAC proteins in living human cells. Eur Biophys J 2009;38:781-791. [PubMed: 19533115]

37. Shah JV, Botvinick E, Bonday Z, Furnari F, Berns M, Cleveland DW. Dynamics of centromere and kinetochore proteins; implications for checkpoint signaling and silencing. Curr Biol 2004;14:942-952. [PubMed: 15182667]

38. Vink M, Simonetta M, Transidico P, Ferrari K, Mapelli M, De Antoni A, Massimiliano L, Ciliberto A, Faretta M, Salmon ED, et al. In vitro FRAP identifies the minimal requirements for Mad2 kinetochore dynamics. Curr Biol 2006;16:755-766. [PubMed: 16631582]

39. Hori T, Haraguchi T, Hiraoka Y, Kimura H, Fukagawa T. Dynamic behavior of Nuf2-Hec1 complex that localizes to the centrosome and centromere and is essential for mitotic progression in vertebrate cells. J Cell Sci 2003;116:3347-3362. [PubMed: 12829748]

40. Hemmerich P, Weidtkamp-Peters S, Hoischen C, Schmiedeberg L, Erliandri I, Diekmann S. Dynamics of inner kinetochore assembly and maintenance in living cells. The Journal of Cell Biology 2008;180:1101-1114. [PubMed: 18347072]

41. McClelland SE, Borusu S, Amaro AC, Winter JR, Belwal M, McAinsh AD, Meraldi P. The CENP-A NAC/CAD kinetochore complex controls chromosome congression and spindle bipolarity. EMBO J 2007;26:5033-5047. [PubMed: 18007590]

42. Kline SL, Cheeseman IM, Hori T, Fukagawa T, Desai A. The human Mis 12 complex is required for kinetochore assembly and proper chromosome segregation. The Journal of Cell Biology 2006;173:9-17. [PubMed: 16585270]

43. Desai A, Rybina S, Muller-Reichert T, Shevchenko A, Hyman A, Oegema K. KNL-1 directs assembly of the microtubule-binding interface of the kinetochore in C. elegans Genes Dev 2003; 17:2421-2435. 
44. Erhardt S, Mellone BG, Betts CM, Zhang W, Karpen GH, Straight AF. Genome-wide analysis reveals a cell cycle-dependent mechanism controlling centromere propagation. The Journal of Cell Biology 2008;183:805-818. [PubMed: 19047461]

45. Cheeseman IM, Chappie JS, Wilson-Kubalek EM, Desai A. The conserved KMN network constitutes the core microtubule-binding site of the kinetochore. Cell 2006;127:983-997. [PubMed: 17129783]

46. Cheeseman IM, Niessen S, Anderson S, Hyndman F, Yates JR 3rd, Oegema K, Desai A. A conserved protein network controls assembly of the outer kinetochore and its ability to sustain tension. Genes Dev 2004;18:2255-2268. [PubMed: 15371340]

47. Welburn JP, Vleugel M, Liu D, Yates JR 3rd, Lampson MA, Fukagawa T, Cheeseman IM. Aurora B phosphorylates spatially distinct targets to differentially regulate the kinetochore-microtubule interface. Mol Cell 2010;38:383-392. [PubMed: 20471944]

48. Kiyomitsu T, Obuse C, Yanagida M. Human Blinkin/AF15q14 is required for chromosome alignment and the mitotic checkpoint through direct interaction with Bub1 and BubR1. Dev Cell 2007;13:663-676. [PubMed: 17981135]

49. Liu D, Vleugel M, Backer CB, Hori T, Fukagawa T, Cheeseman IM, Lampson MA. Regulated targeting of protein phosphatase 1 to the outer kinetochore by KNL1 opposes Aurora B kinase. J Cell Biol 188:809-820. [PubMed: 20231380]

50. Obuse C, Iwasaki O, Kiyomitsu T, Goshima G, Toyoda Y, Yanagida M. A conserved Mis12 centromere complex is linked to heterochromatic HP1 and outer kinetochore protein Zwint-1. Nat Cell Biol 2004;6:1135-1141. [PubMed: 15502821]

51*. Davies AE, Kaplan KB. Hsp90-Sgt1 and Skp1 target human Mis12 complexes to ensure efficient formation of kinetochore-microtubule binding sites. J Cell Biol 2010;189:261-274. This paper describes a complex of proteins that acts as a "chaperone" for the Mis 12 complex, promoting its assembly at the kinetochore. [PubMed: 20404110]

52. Amano M, Suzuki A, Hori T, Backer C, Okawa K, Cheeseman IM, Fukagawa T. The CENP-S complex is essential for the stable assembly of outer kinetochore structure. The Journal of Cell Biology 2009:1-10.

53. Zuccolo M, Alves A, Galy V, Bolhy S, Formstecher E, Racine V, Sibarita JB, Fukagawa T, Shiekhattar R, Yen T, et al. The human Nup107-160 nuclear pore subcomplex contributes to proper kinetochore functions. EMBO J 2007;26:1853-1864. [PubMed: 17363900]

54. Orjalo AV, Arnaoutov A, Shen Z, Boyarchuk Y, Zeitlin SG, Fontoura B, Briggs S, Dasso M, Forbes DJ. The Nup107-160 nucleoporin complex is required for correct bipolar spindle assembly. Mol Biol Cell 2006;17:3806-3818. [PubMed: 16807356]

55*. Mukhopadhyay D, Arnaoutov A, Dasso M. The SUMO protease SENP6 is essential for inner kinetochore assembly. The Journal of Cell Biology 2010;188:681-692. This paper describes the importance of the SUMO protease SENP6 in the incorpration of CENP-I at the kinetochore. [PubMed: 20212317]

56. Peters JM. The anaphase promoting complex/cyclosome: a machine designed to destroy. Nat Rev Mol Cell Biol 2006;7:644-656. [PubMed: 16896351]

57. Gurden MD, Holland AJ, van Zon W, Tighe A, Vergnolle MA, Andres DA, Spielmann HP, Malumbres M, Wolthuis RM, Cleveland DW, et al. Cdc20 is required for the post-anaphase, KENdependent degradation of centromere protein F. J Cell Sci 2010;123:321-330. [PubMed: 20053638]

58. Cheeseman IM, Anderson S, Jwa M, Green EM, Kang J, Yates JR 3rd, Chan CS, Drubin DG, Barnes G. Phospho-regulation of kinetochore-microtubule attachments by the Aurora kinase Ipl1p. Cell 2002;111:163-172. [PubMed: 12408861]

59. DeLuca JG, Gall WE, Ciferri C, Cimini D, Musacchio A, Salmon ED. Kinetochore microtubule dynamics and attachment stability are regulated by Hec1. Cell 2006;127:969-982. [PubMed: 17129782]

60. Emanuele MJ, Lan W, Jwa M, Miller SA, Chan CSM, Stukenberg PT. Aurora B kinase and protein phosphatase 1 have opposing roles in modulating kinetochore assembly. The Journal of Cell Biology 2008;181:241-254. [PubMed: 18426974] 
61**. Kawashima SA, Yamagishi Y, Honda T, Ishiguro K, Watanabe Y. Phosphorylation of H2A by Bub1 prevents chromosomal instability through localizing shugoshin. Science 2010;327:172177. This important study identifies histone H2A as the substrate for the mitotic kinase Bub1, and describes the mechanism by which this phosphorylation controls the protection of centromeric cohesion. [PubMed: 19965387] 


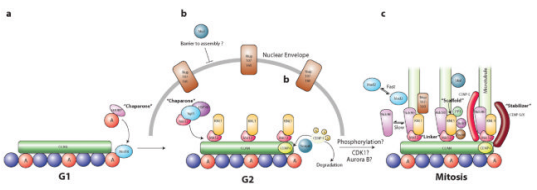

Figure 1.

Schematic representation of kinetochore assembly in human cells. A) The CCAN proteins are present at the centromere throughout the cell cycle. In late telophase and early G1, new CENP-A containing nucleosomes are deposited via the Mis 18 complex and the HJURP "chaperone". B) During G2, a subset of kinetochore components such as the Mis12 complex and KNL1 assemble at the centromere, while others maybe excluded by the nuclear envelope. The Sgt/HSP90 complex acts as a "chaperone" to promote recruitment of the Mis12 complex, while the SENP6 SUMO protease regulates assembly of the CCAN protein CENP-I. C) On entry into mitosis the bulk of the kinetochore is recruited to the centromere. This process is likely regulated by phosphorylation by mitotic kinases. Some components, such as the Mis12 complex, act as "linkers", while others such as KNL1 act as "scaffolds" for the recruitment of multiple other components. Finally, other proteins such as the CENPS/X complex act to "stabilize" the structure. Kinetochore components display different dynamics during mitosis, with some proteins such as Mad2 turning over rapidly, but others such as Ndc80, turning over more slowly. 